\title{
Y si no fuera por el hueso: escritura autoetnográfica de un hombre y enfermero
}

And if it wasn't for the bone: autoethnographic writing of a man and a nurse E se não fosse pelo osso: escrita autoetnográfica de um homem e uma enfermeira

\section{Luis Alexander Lovera Montilla ${ }^{1}$}

${ }^{1}$ Candidato a Doctor en Salud, Magister en Epidemiología, Enfermero Neonatal. Universidad del Valle, Cali-Colombia. Orcid: https://orcid.org/0000-0002-8557-4278. Correo electrónico: luis.alexander.lovera@correounivalle.edu.co

Correspondencia: Escuela de Enfermería. Calle 4B \# 36 - 00 Ed. 110. Universidad del Valle, Cali-Colombia

Para citar esta editorial: Lovera Montilla, L.A. (2021). Y si no fuera por el hueso: escritura autoetnográfica de un hombre y enfermero. Cultura de los Cuidados, 25(61). Recuperado de http://dx.doi.org/10.14198/cuid.2021.61.04

Recibido:21/05/2021 Aceptado: 09/09/2021

\section{RESUMEN}

Reflexionar desde la experiencia vivida, para construir conocimiento a través de ella misma, ha sido esencial para tejer este texto. El cual, es un pedazo de mi investigación doctoral. Objetivo: Describir y analizar simultáneamente aspectos familiares, profesionales como enfermero y personales, subsumidos en una estructura social. Método: A partir de la metodología autoetnográfica, pretendo acercarme a la investigación y a la escritura, buscando describir y analizar sistemáticamente una experiencia personal para entender la experiencia cultural. Utilizo la narración en capas con el propósito de mostrar una experiencia dialéctica, en donde, aparecen diferentes voces reflexivas que producen e interpretan el texto. Resultados: emergieron asuntos: la relación con mi padre, el machismo familiar y el contexto donde me moví, la pedagogía del dolor, la asimetría de poder, estas dos últimas que corresponden según lo narrado y atestiguado por mí, a una estructura de conocimiento encastrada en un sistema patriarcal, enraizada y perpetuada desde lo familiar hasta lo social, pasando por la institución de conocimiento, la universidad. Conclusión: La autoetnografía es una metodología de investigación que centra la atención a la propia experiencia. Que, para este caso, hace referencia a la construcción de conocimientos desde mi posición como enfermero y hombre.

Palabras Clave: Autoetnografía; enfermería; machismo; asimetría de poder 
ABSTRACT

Reflecting from lived experience, to build knowledge through it, has been essential to weave this text. Which is a piece of my doctoral research. Objective: To simultaneously describe and analyze family, professional, and personal aspects, subsumed in a social structure. Method: From autoethnographic methodology, I intend to approach research and writing, seeking to systematically describe and analyze a personal experience to understand the cultural experience. I use layered narration in order to show a dialectical experience, where different reflective voices appear that produce and interpret the text. Results: issues emerged: the relationship with my father, the family machismo and the context where I moved, the pedagogy of pain, the asymmetry of power, the latter two that correspond, according to what was narrated and witnessed by me, to an embedded knowledge structure in a patriarchal system, rooted and perpetuated from the family to the social, passing through the institution of knowledge, the university. Conclusion: Autoethnography is a research methodology that focuses attention on one's own experience. Which, for this case, refers to the construction of knowledge from my position as a nurse and a man.

Keywords: Autoethnography; Nursing; sexism; power asymmetry

\section{RESUMO}

Refletir a partir da experiência vivida, por meio dela construir conhecimento, foi essencial para tecer este texto. Que é um pedaço da minha pesquisa de doutorado. Objetivo: Descrever e analisar simultaneamente os aspectos familiares, profissionais e pessoais, subsumidos em uma estrutura social. Método: A partir da metodologia autoetnográfica, pretendo abordar a pesquisa e a escrita, buscando descrever e analisar sistematicamente uma experiência pessoal para compreender a experiência cultural. Uso a narração em camadas para mostrar uma experiência dialética, onde aparecem diferentes vozes reflexivas que produzem e interpretam o texto. Resultados: emergiram questões: a relação com o meu pai, o machismo familiar e o contexto onde me mudei, a pedagogia da dor, a assimetria do poder, estas duas últimas que correspondem, segundo o que foi narrado e testemunhado por mim, a um encaixado estrutura do conhecimento em um sistema patriarcal, enraizado e perpetuado desde a família até o social, passando pela instituição do conhecimento, a universidade. Conclusão: a Autoetnografia é uma metodologia de pesquisa que focaliza a atenção na própria experiência. O que, neste caso, se refere à construção do conhecimento a partir da minha posição de enfermeira e de homem.

Palavras-chave: Autoetnografia; Enfermagem; sexismo; assimetria de poder

Los textos tienen sin duda aspectos estimulantes que perturban y con esto se causa esa nerviosidad que Susan Sontag quiere designar como el erotismo de las artes

Wolfgang Iser 
He querido iniciar este texto con un epígrafe, el cual me sirve como preámbulo para hacer referencia a la relación dialógica, que espero, tenga este texto autoetnográfico evocativo, que hace parte de uno de los momentos dentro de mi tesis doctoral. Se han utilizado los asteriscos para indicar el cambio de posicionalidad temporal y espacial dentro del texto, de igual manera aparecen yuxtapuestas las capas evocativas y analíticas. No obstante, espero poder trasmitir más que emotividad, abro el texto para que el lector asuma una postura y comprometerlo en el ejercicio de contraste y crítica.

A partir de la narración en capas que he llevado a cabo en este viaje de escritura, que inició, situándome en un evento, como lo fue la lesión de un hueso. Un hueso mío. Llegar a entender como la rotura del hueso, más que una descripción de una situación desagradable, me llevo a reflexionar, acerca de una serie de asuntos, como por ejemplo, la relación con mi padre, el machismo presente en mi familia y el contexto donde me moví, la pedagogía del dolor, la asimetría de poder, estas dos últimas que corresponden según lo narrado y atestiguado por mí, a una estructura de conocimiento encastrada en un sistema patriarcal, enraizada y perpetuada desde lo familiar hasta lo social, pasando por la institución de conocimiento como lo es la universidad. Han surgido una serie de preguntas, pero son tres las que guían el desarrollo de este texto: ¿qué hubiera pasado si no se da la discusión con papá?, ¿`si no hubiera golpeado la pared? ¿Por qué tuve que esperar tanto tiempo para narrar lo escrito? Estos, y otros aspectos que menciono en el cuerpo del texto, son los que con el tiempo se han tensionado y, que constituyen la base de este documento, que han tenido algún efecto en mi corporeidad.

Finalmente, haberme situado en el campo social para interpretar este asunto mío, de la rotura de un hueso, y a la vez, el de los otros, con mi formación como clínico y docente, me ha resultado revelador, al reconocer que este ejercicio de escritura acerca de nuestras vidas, va más allá de contar una simple historia; es mostrarla. Acogiéndome a Ellis y Bochner, autores seminales de este estilo autoetnográfico quienes señalan que el mundo social es un mundo de conexiones, contacto y relaciones; además, donde las consecuencias, valores, políticas y dilemas morales están a la vuelta de la esquina, en donde teorizar se concibe como una actividad social y comunicativa (Bochner, 1997; Ellis, 2016). De igual forma, y en palabras de José Siles: “los trabajos que contribuyen a clarificar la evolución de lo que denominamos -colectivos esenciales-, aquellos que 


\section{6}

están profundamente vinculados a estructuras básicas de la sociedad, son grupos que han formado parte de lo cotidiano, lo doméstico y cuyo proceso de profesionalización resulta imposible de entender sin el concurso de la historia y la antropología. Para colectivos como la enfermería, antropología e historia (Siles, 2000; Siles et al., 2005).

$* * *$

Era el año 2000, comienzo de un nuevo siglo. Me encontraba en Bogotá visitando a mis padres, después de casi un año sin verlos. Normalmente, acostumbro a ir dos o tres veces al año. Las últimas veces viajaba en carro cerca de nueve horas. Sin embargo, esta vez lo hice por avión.

Por lo general, esas estadías en casa de papás eran de dos semanas. Sin embargo, en esta oportunidad, las cosas serían diferentes. Una de esas noches, tuve una discusión con mi padre. No recuerdo exactamente el motivo del disgusto. Mi papá y yo hemos tenido una relación tensa y no muy cordial, debido al comportamiento agresivo y machista de él. El cual, desafortunadamente para nosotros como familia fue alimentado por el consumo de alcohol y cigarrillo. Lo anterior lo experimenté los primeros 19 años de mi vida, tiempo en el que viví con mamá y papá.

Algunas instituciones sociales como la familia, obedecen a necesidades psicológicas de los grupos, necesidades determinadas por las condiciones familiares. En donde, esa adulación a la masculinidad y a la supremacía de ésta, es avalada por el género contrario (Torres \& Delgado, 2018; Urías, 2016). Para mi caso, mi madre, que siempre acepto sistemáticamente ese comportamiento, diciendo: mijo, no le parara bolas a lo que su papá hace y dice; es decir, haciendo referencia a que no lo escuche, deje que lo grite, que lo agreda verbalmente, que eso no pasa nada, y verá que ya se le pasará, para pelear se necesitan dos, eso siempre lo decía mamá. Así, ella me hacía recordar en mi infancia, como ella toleraba, que él la golpeara y yo allí observando.

Nos encontrábamos los dos en el segundo piso de la casa. Él me habló casi gritándome, cosa que me ha incomodado toda la vida. Acostumbraba años atrás a hacerlo con frecuencia, como imponiendo su poderío de macho. Sin embargo, él en ese momento 
se encontraba frente a un hombre y no frente al niño que lo había registrado y grabado por años.

Lo que rememoro, después de más de dos décadas, es lo que sintió mi cuerpo, en especial una parte de él: mi mano derecha. Recuerdo que giré mi cuerpo bruscamente, producto de la rabia que experimenté en ese momento, y con ella, mis manos siguieron un movimiento brusco, como si la rabia las hubiera poseído. Lo que llevó a que mi mano derecha se estrellara contundentemente justo contra el filo del marco de la puerta. Ahí sentí un dolor tremendo, como si la mano se hubiera estallado. Esa fue la última noche, que pasé esa vez en Bogotá.

Mi reacción inmediata fue recoger mi mano, llevándola hacia el centro del cuerpo; como abrigándola, envolviéndola para cuidarla. En ese momento, fruto del calor y la exaltación por lo sucedido, tome la decisión de regresarme de nuevo a Cali, a mi casa, porque sabía que me había lastimado y lo más seguro es que, por la sintomatología, iba a terminar en urgencias.

Así las cosas, espere a que amaneciera para dirigirme al aeropuerto a comprar el pasaje. Me dolía mucho la mano, toda la noche tuve dolor, a pesar de que me auto mediqué fuertemente. Sentía dolor, no podía mover los dedos, dado que se encontraban muy inflamados. El viaje en el avión fue estresante. Dos o quizás tres personas me golpearon la mano sin intención, a pesar de que la noche anterior me había vendado y era visualmente reconocible el vendaje, no valió de nada haber refugiado mi mano en el centro de mi cuerpo con ese vendaje.

Apenas llegué a Cali, me dirigí de inmediato a la clínica, consulté por urgencias. Me vio el médico. Coincidencialmente ese día, el ortopedista estaba por ahí. Me tomaron rápidamente las imágenes diagnósticas. Efectivamente me había fracturado uno de los metacarpianos y dos falanges del quinto dedo, fue lo que apareció en las radiografías. Me dieron más analgesia, pues el ortopedista, en principio, me dijo que me tenía que alinear la mano. Sentí más dolor, parecía que la analgesia era solo un placebo, porque no tuvo ningún efecto sobre mí. El dolor aumentó cuando él jaló fuertemente mis dedos para 


\section{8}

estirarlos, es decir, para reducir en términos clínicos la fractura con el propósito de organizar las estructuras óseas.

Después de eso, y de haberme enyesado la mano, me dijo que además de la fractura, había encontrado unas lesiones que le llamaban mucho la atención en varias partes de esta. Motivo por el cual, él me remitiría con las órdenes médicas y la historia clínica para que hiciera el trámite de autorizar estos documentos para conseguir cita con el subespecialista en oncología ortopédica.

Fueron pasando los días y era imposible conseguir la cita con el oncólogo ortopedista que me habían recomendado, una eminencia en su campo, en Latinoamérica -pues de esa manera me lo referenciaron- y que, para alegría mía, vivía en mi ciudad. La asignación de citas con él tenía lista de espera para 4 meses. Finalmente, algún conocido me ayudó y pude lograr una cita en su consultorio particular 15 días después, tiempo en el cuál, pensé muchas cosas sobre esas famosas lesiones, preguntándome: ¿por qué me habían aparecido? y, del mismo modo, pensando que seguramente era un tumor. Como tenía que sustentar mi incapacidad laboral, se dieron cuenta del diagnóstico y de lo que se estaba investigando.

No sé cómo se enteraron mis compañeros de trabajo. Tuve que volver al hospital a radicar nuevamente la incapacidad, dado que, en principio, la copia de la historia clínica había salido borrosa. Una compañera, al verme llegar con el yeso, se lanzó con cuidado hacia mí, me dio un fuerte abrazo y me dijo: confía en Dios que todo saldrá bien. Llegaron otras, he hicieron lo mismo, me abrazaron y se pusieron a llorar. Me expresaron que no me preocupara, que todo iba a salir bien. Otra me dio una imagen y una oración del divino niño. No entendía lo que sucedía, todo paso tan rápido y repentino. Pero no sé qué carajos les estaba pasando, ya me habían enterrado, según ellos estaba cursando con un cáncer y me estaban dando ánimos. ¡Pero cómo! Si ni siquiera me había visto el oncólogo, de dónde sacó esta gente esta locura. Si, cuando el ortopedista me remitió con el oncólogo, se me abrió, a mí como paciente, la posibilidad de una lesión tumoral, pues uno tiene un espectro de lesión benigna a maligna, pero esta gente ya me había crucificado con un cáncer. Sentí malgenio por sus pobres deseos de apoyo. Yo solamente fui a llevar una incapacidad, no ha recibir un sentido pésame. 
Salí del hospital consternado entre la risa y la rabia por la incertidumbre que se me había creado. Ahora era mayor a la que ya tenía. Me preguntaba: ¿y qué tal que si de verdad tuviera cáncer?, ¿quién iba a cuidar a mi hija? Ese tipo de cosas me fui cuestionando camino a la salida del hospital y en todo el recorrido del taxi hasta la casa. Pasaron como diez días hasta que logré conocer al oncólogo ortopedista, un hombre blanco, pelo negro, ojos verdes y vos gruesa, me vio por primera vez. El día que fui a su consultorio me di cuenta que no era el único, pues la cita me la habían dado para las 2 pm y me atendió casi hasta las 4pm. No entendía qué pasaba, por qué tanta demora, si incluso había llegado una hora antes. Lo que sí había notado era que, cuando llegué, es que serían varias personas las que estábamos en espera. Me acerqué como dos veces a preguntarle a su secretaria qué era lo que sucedía, por qué no me atendían. Ella me dijo que estaba un poco atrasado y que ese día eran varios los pacientes programados, motivo por el cual era la demora en la atención.

Sin embargo, al entrar y conocer al famoso oncólogo ortopedista, pude darme cuenta que lo que me informó la secretaria era totalmente falso, pues este especialista era famoso y tanto sus citas del hospital público como de su clínica y consultorio privado eran apretadas. Por lo que su modus operandi, era tener tres consultorios programados en paralelo, es decir, que éramos tres pacientes de las 2 pm y que nos veía a los tres en consultorios diferentes al mismo tiempo, supuestamente.

La verdad me incomodó aún más, cuando me di cuenta de todo esto, intenté decírselo, pero él, inició la anamnesis y la valoración física cálidamente de manera académica y me convenció de no hacerlo. En menos de veinte minutos, me había programado toda una batería de exámenes y en dos hojas de papel me había explicado y dibujado detalladamente, con lápices de colores, la lesión y el plan de manejo que proponía. Igualmente, dejó todo organizado para una posible cirugía, era como si hubiera predicho el diagnostico final. Pues, me dijo: yo creo que lo que tienes es una encondromatosis. La encondromatosis es una lesión que se localiza en el hueso, principalmente en el cartílago, dichas lesiones son generalmente benignas, sin embargo, su principal complicación es la transformación a la malignidad denominada condrosarcomas. La cirugía que me había comentado el doctor, consistía en hacer la 


\section{0}

resección ósea de las lesiones, en otras palabras, es quitar el tejido malo y con él, las lesiones, luego rellenar esos espacios con hueso de un difunto; es decir, me iba a colocar un injerto con hueso cadavérico. De tal manera, que tuve que comprar 3 gramos de hueso cadavérico, que en ese entonces me costó cerca de 2 millones de pesos colombianos en un banco de hueso. Entonces, no todo mi cuerpo es mío, hay parte de alguien dentro de él, de un ser desconocido que me acompaña.

Ahora me pregunto ¿qué hubiera pasado si no se da la discusión con papá?, ¿¿si no hubiera golpeado la pared? ¿Si no me hubiera fracturado el hueso esa noche? Seguramente, en algún momento las lesiones se hubieran expresado, hubieran aparecido de la nada o siempre estarían enmascaradas. Lo que no estoy seguro, es si su benignidad hubiera cambiado o si el diagnóstico hubiera sido muy tarde, para hacer la prevención como la he venido realizando en los últimos veinte años. Ese evento, a través del trauma, condujo a un diagnóstico secundario, a un descubrimiento que no estaba dentro del estimado de una simple fractura. La fractura entonces, fue un medio para llegar al desenlace final del encondroma.

Hoy me pregunto, y no porque inicialmente se me haya ocurrido a mí, sino por las conversaciones académicas que he venido sosteniendo con un maestro en letras que he conocido en las últimas semanas, quien me hizo ver el carácter simbólico del golpe como acción de desahogo, pero a la vez de demostración de energía, destello de fuerza y que, por lo general, está relacionado con el género masculino. Recapitulando acerca de esto, he visto muchas escenas provocadas en su mayoría por hombres, de facto, esa escena del golpe se la he visto a mi padre en otras ocasiones.

Pero solo hasta ahora que escribo este corto texto, tomo conciencia de las implicaciones del golpe, no solo como un acto de desahogo y de la expulsión de los demonios que llevaba dentro de mí, sino en la naturalización de este tipo de formas de expresión de machismo. Es más, en mi vida han sido poco los escritos, por decir dos o tres, en los que toco esta categoría de superioridad producto del género. Pero en los últimos tiempos, gracias a mis estudios de doctorado y a las posibilidades de leer y 
untarme de otras disciplinas y otras miradas distintas a la mía y a mi formación que me permite confrontar algunos asuntos, como, por ejemplo, esto del golpe en una pared. Sin embargo, ahora me estoy inquietando por esta cuestión del machismo, muy marcado, tanto en mi familia paterna como materna y, cómo incorporé en mi maleta de viaje muchas actitudes, discursos y prácticas machistas. Pero hago un alto, y me confronto con mi formación disciplinar, en donde los hombres éramos menos del 8\%. Experimenté varias escenas, no sé si llamarlas de machismo, pues eran mujeres -profesoras y compañeras en su mayoría- las que utilizaban su lenguaje descalificador y algunas actitudes hacia mí, y otros compañeros que nos estábamos formando como enfermeros.

Me encontraba cursando séptimo semestre de enfermería, tenía una profesora que era un ejemplo de admiración para muchos, incluso para mí también, ella era o es enfermera, no sé si vive ahora, formada en estudios superiores en la Universidad de Austin, Texas. Especialista y con maestría en cuidado intensivo. Por alguna razón, que ella no supo, no pude asistir a un examen parcial de su asignatura, porque toda la situación se dio tan improvisto, además en ese tiempo las comunicaciones eran limitadas. Finalmente, al no asistir a cumplir con mi deber, como estudiante de presentar el examen, la nota que me califico fue cero. Como la situación había sucedido un viernes, solo tuve opción de buscarla muy temprano en su oficina el día lunes. Me presente, no levanto la cara para saludar, ni mucho menos para ver quien la había saludado. Volví y me presenté, por supuesto, ella sabía quién era yo, ya que, llevaba cerca de tres meses tomando su asignatura y compartiendo la práctica clínica con ella. Le dije que no había podido estar en el examen, dado que mi abuela había fallecido producto de una infección que venía cursando, sumado a un infarto cardiaco. Motivo por el cual, me había quedado difícil asistir e informar. Me miro a los ojos y me dijo: eso es mentira, todos sus compañeros hombres tienen siempre la excusa perfecta, por la nota no se preocupe pues, mire la cartelera, mire su código y nombre ahí está su cero. Esas fueron sus palabras esa mañana.

Salí de esa oficina, con el rabo entre las patas, como un perro regañado. No module, ni fui capaz de refutar palabra alguna. Ella desde el primer día en que se presentó, nos sentenció a los pocos hombres que éramos en el semestre, diciendo algo como: de ustedes enfermeros hombres esperare mucho y estaré observándolos detenidamente. De 
hecho, además de un profundo respeto que sentía por esa profesora de aspecto militar, de voz grave, de 1,75 metros de altura y con una contextura gruesa y facies fuertes, sentía siempre mucho temor, en clase preguntaba hasta el fondo, pero a nosotros los hombres nos preguntaba más, nunca estaba conforme con nuestras respuestas.

Me devolví para mi casa. Tome el trasporte público, que, por lo general, se tomaba en tiempo cerca de dos horas entre la universidad y mi casa, un solo trayecto, es decir, serían diariamente cuatro horas, pero ese día iban a ser seis. Llegue a casa, no había nadie, mamá y papá estaban en sus trabajos. Así que tomé uno de esos papeles impresos en papel periódico con letra arábiga de 1 metro por 1 metro que entregan las funerarias, para que la familia invité a la comunidad al velorio y funeral cuando alguien muere. Me dirigí apresuradamente a donde una tía para que me permitiera sacarle una fotocopia al certificado de defunción de la abuela.

Así las cosas, de regreso otra vez a la universidad en horas de la tarde, me dirigí envalentonado y cargado emocionalmente, a buscar a esa profesora. Afortunadamente, la encontré en su oficina. Entre, no me anuncié con su secretaria como es de costumbre y norma, sino que me dirigí a su escritorio directamente. Estaba allí sentada revisando unos papeles, no recuerdo si estaba con alguien más en ese espacio, solo sé, que quería verla a los ojos y decirle, que yo no era un mentiroso, eso hice literalmente. La llamé por su nombre, le dije que necesitaba hablar con ella, me dijo que no teníamos nada de qué hablar. Acto seguido, le tire en su escritorio el certificado de defunción de la abuela, lo mismo el aviso de invitación al velorio y funeral. Yo esperaba una reacción inmediata de ésta profesora, solo me miro a los ojos y no dijo palabra alguna. Ni siquiera se detuvo a revisar lo que estaba en el escritorio. No me demoré más de 1 segundos y salí de allí. Dos días después, me había citado a su oficina para presentar el examen, ella no estuvo, fue su secretaria la que lo supervisó. Finalmente, pasé la prueba con un tres sobre cinco. Nunca más volví a cruzar palabra o mirada con esta profesora, ya no teníamos que volvernos a ver. La nota final de su práctica clínica y de teoría me había apenas alcanzado para pasar la asignatura, la cual, era requisito para poder graduarme en el siguiente semestre.

Volviendo a mi cuerpo, hoy me miro mis manos, si bien la lesión fue en la derecha, necesito como buen clínico que soy, compararla con algo y la medida gold estándar, pues 
era mi otra mano. Es como si durante estos años, haciendo una semejanza al control de crecimiento y desarrollo que se le lleva a un infante, para mirar si su peso y talla salen del estimado estadístico reflejado en una curva con percentiles de normalidad y anormalidad. En mi caso, por supuesto, no llevaba gráfica alguna, todo era comparación directa con mi estándar, la mano con mis huesos propios vs la mano compartida con otro u otra. Porque no sé de quién es el hueso y no me interesa saberlo. El punto es que, en estos procesos tumorales benignos, siempre hay un grado de incertidumbre en la aparición de cambios corporales, de laboratorios séricos e imágenes que puedan ser sugestivos de alguna diferencia. Motivo por el cual el paciente, en este caso yo, debe comprometerse con su autocuidado, asistencia a los controles y exámenes periódicos.

De esa manera fueron pasando los controles médicos con mi oncólogo, año tras año, cada semestre. Me reunía en su consultorio, siempre con las radiografías comparativas de ambas manos. Recuerdo que, en una ocasión, me solicitó una radiografía de humero derecho. Yo me la tomé y se la llevé para que la revisará. Era como si ése médico, además, de ser clínico fuera un brujo, pues su razón había tenido para enviármela. El resultado, era una lesión en humero parecida por imagenología a las anteriores lesiones en la mano. La situación a mí ya se me complicaba, dado que, mi trabajo venía en aumento, laboraba en tres hospitales, estábamos ahorrando para terminar de pagar la casa y un carro nuevo que habíamos sacado con un crédito. Además, del apoyo económico que les hacía cada mes a mis padres.

Mi oncólogo ortopedista me había dicho, llamándome por mi apellido: tranquilo Lovera, no hay nada que preocuparse, eso no va a crecer ni le van a salir más, en otras partes. Me lo dijo con un poder de convencimiento. Salí ese día del consultorio más convencido que nunca, de que todo iba por buen camino. Y la verdad, así fue. La recomendación era una sola: Nunca fallar en los controles médicos e imagenológicos, además de estar atento a observar cambios en la forma de mis manos o en cualquier cambio que viera en mi cuerpo.

Por otro lado, había algo que me llamó mucho la atención de mi oncólogo. Fue la relación tan estrecha que pude atestiguar con la mayoría de sus pacientes, incluyéndome a mí. Era una figura de un galeno diferente, serio, sincero y muy humano como lo había reconocido en párrafos anteriores. Esa relación tan estrecha y solida que veía, cada vez 
que consultaba y conocía a la vez, las historias de otros pacientes, es lo que quiero relievar en ése médico. Era una entrega de su conocimiento, colocando todo su saber en función de la recuperación y rehabilitación de los que estábamos allí, pero a la vez brindando esperanza, dado que, incluso los casos más difíciles de sus colegas eran comentados, discutidos y a veces solucionados por él. En las consultas era común, escuchar vía telefónica solicitud de otros colegas, incluso, como yo soy del sector salud, había cierto grado de apertura y me comentaba sobre lo largas de sus jornadas en Colombia y en otros países, casos insólitos, etc. Actitud positiva y resolutiva, además de unos valores hacia sus pacientes, que, a la luz de hoy, son difíciles de encontrar en un profesional como lo era ese doctor.

Sin embargo, no todo era color de rosa. En contraste, a esa forma de llegar a sus pacientes y, de compenetración con su estado de salud, a la vez, con la historia de cada uno de ellos. Observaba un comportamiento que me incomodaba, es más, no lograba entender como adentro del consultorio su discurso y su corporalidad era diferente con uno, pero afuera de esas coordenadas, su comportamiento autoritario, rayaba con lo pedante y agresivo hacia sus subordinados, secretarias, personal administrativo, residentes y colegas. De hecho, cuando algún personal de salud que había tenido la oportunidad de interactuar con este doctor, hacían referencia exaltando primero su trabajo con lo académico y acto seguido la crítica fuerte a su manera de ser y comportarse en el terreno clínico y quirúrgico, en relación al trato y al lenguaje que utilizaba para comunicarse y tratar a los otros, colegas, enfermeras, circulantes, estudiantes y residentes. Tenía una pedagogía fuerte para transmitir y para corregir a otros, tuve esa oportunidad de ver esto en escenarios clínicos y académicos. Nunca comprendí esa dualidad como persona, si bien, yo en su momento era simplemente un paciente que necesitaba una resolución a un asunto de salud, también tenía puesta la camisa de un profesional de salud, que conocía las estructuras clínicas y biomédicas en las que nos movemos nosotros, pero me resistía a creer en la presencia de esas dos caras, en mi oncólogo ortopedista. Años después, cuando me convierto en profesor universitario y lo veía entendí, más nunca compartí su manera de enseñar y sobreponerse ante el otro, como si fuera necesario, enseñar con dolor. 
Deseo retomar la idea anterior, apelando al trabajo etnográfico de Roberto Castro (2014) en el que yo, pude ver, al leerlo. Cómo las dinámicas de los servicios de salud en los que me he venido movilizando através de más de 26 años, en el ejercicio clínicodocente, no solo, en los que señala el autor; es decir, a los del área materno perinatal, sino que, además, se puede extrapolar a otras áreas. Por supuesto, conociendo también ese cordón umbilical comunicativo y asistencial que existe, entre las salas de parto/cesárea y las unidades de cuidados intensivos neonatales, en donde, las presencias de algunas conductas no solamente están arraigadas en los profesionales de medicina, sino en la enfermera-o y a otros profesionales que acompañan la asistencia en cualquier área clínico - quirúrgico - asistencial.

Para referirme a aquellas conductas pedagógicas en la enseñanza y aprendizaje en los escenarios clínicos. En donde, se lesiona, vulnera, intimida, ofende la dignidad humana del que aprende en su formación y, de paso, la del sujeto que recibe cuidado. Castro señala que, al rastrear, en el encuentro entre la estructura del campo médico y el habitus de los profesionales de la salud, se puede conocer el origen social del autoritarismo que lleva a los prestadores de los servicios de salud a violar ciertos derechos (Castro, 2014). Es a partir desde esos años, donde, uno empieza a formarse como enfermero-a, médico, fisioterapeuta, a la vez, se va constituyendo un habitus, tomando el concepto de Bourdieu (Bourdieu, 1993). Para el caso de la investigación de Castro, fue el habitus médico, sobre todo a partir del currículum oculto, habitus que tal como él lo señala, se convertirá posteriormente en un elemento sustancial para comprender acerca del autoritarismo al que esos profesionales normalizarán durante su práctica profesional y docente (Castro, 2014).

Eso mismo que yo resaltaba en el comportamiento de ese doctor, me trajo recuerdos, cuando me forme en la Universidad. Mis docentes, no todas y algunas compañeras, pero más aún mis docentes, me enseñaron a través del dolor, de infligirme dolor, no un dolor físico, sino un dolor emocional, anímico, hasta intelectual, un dolor que se hace crónico y que mina en lo personal y trasciende a lo profesional. Sin embargo, ahora, reflexiono, que al ver vivido las dos situaciones, al haber tenido esas experiencias en mi rol actual, desde que me inicie en el camino de la docencia tenía claro que no quería 


\section{6}

tener el espejo de algunas de ellas. No obstante, hoy mentiría si negará que alguna vez, también llegué a comportar con otros de manera irónica y utilizando el castigo, castigo no físico, como herramienta pedagógica; yo también lo ejecuté, con mis estudiantes de pregrado y posgrado y hoy, reconozco más que nunca, a través, de este texto, la reproducción que hice de esa práctica y comportamiento aprendido algún día y, nutrido incluso en el hospital universitario donde laboré muchos años.

Tratando, de parafrasear un poco a Rita Segato, si el acto violento, que, para mi caso, es entendido desde lo pedagógico, en el lenguaje y las prácticas, entendido como un mensaje, y en las propias palabras de Segato: cuando un sistema de comunicación con un alfabeto violento se instala, es muy difícil desinstalarlo. La violencia constituida y cristalizada en forma de sistema de comunicación se transforma en un lenguaje estable (Segato, 2013). Si bien lo anterior, fue escrito para denunciar un contexto de violencia contra las mujeres, considero que, que para el asunto al que haga referencia como hombre, tiene cierto grado de aplicabilidad. Si bien, los escenarios y contextos son diferentes lo mismo que los géneros, el fenómeno social de la violencia es transversal. En este caso, la intimidación, amenaza verbal que tenía también, una traducción al lenguaje no verbal, fue perpetuado por el género femenino. Perpetuación que se hizo constante no solo en mí sino en otros hombres, en historias de otros estudiantes hombres que hablaban de ella como una inquisidora, como recordando la categoría analítica de Segato de pedagogías de la crueldad, para hacer referencia a los actos y prácticas que enseñan, habitúan y programan a los sujetos a transmutar lo vivo y su vitalidad en cosas (Segato, 2018).

Me pregunto hoy, ¿cuántas veces cosifiqué a una estudiante o a un estudiante? ¿Cuántas veces las y los trate como me trataron a mí? ¿Cuántas veces para mí simplemente fueron un apellido y un código?

Ya en mi vida familiar y profesional, siempre los movimientos con mi mano derecha estaban controlados y regulados de manera sistemática e inconsciente, es decir, protegía constantemente la mano y si había que realizar alguna actividad que implicará al menos un movimiento brusco, mi instinto de protección actuaba inmediatamente. Fueron pasando los meses y años y todo fluía perfectamente, el injerto óseo se había consolidado. 
Mi mano estaba funcional, lo único que no se podía cambiar era una ligera desviación, bueno no tan ligera, más bien acentuada desviación del cuarto y quinto dedo. Desviación que nunca tuvo una repercusión alguna.

En casa, cuando jugaba con mi hija, siempre me preguntaba: papá por qué te cuidas tanto la mano. Ella aprendió que era prohibido golpear a su padre en la mano, dado que ahí estaba una especie de cristal. La verdad es que incluso hoy, mi mano la veo como un cristal, como algo frágil, a pesar de que ella es muy funcional.

En agosto del año 2016, me había enterado de una nefasta noticia, de la muerte de un hombre en las playas de Cartagena, en presencia de sus familiares. Pues esta persona era experta en esta práctica, la noticia circulo por todos los medios, en especial vía redes sociales. Se trataba, nada más ni nada menos, de mi oncólogo ortopedista, el médico con el que venía llevando una relación terapéutica de más de 16 años. Ese Buzo, y a la vez médico, me había detectado y tratado una lesión tumoral de manera efectiva. En la cual, yo y seguramente muchos pacientes en Colombia y por supuesto, en otras latitudes de Latinoamérica estarían sintiendo lo mismo que yo o al menos echándolo de menos. Esa seguridad que propiciaba este ser, en esa relación médico-paciente, una relación abierta y sincera, era la que me estaba doliendo. Pensé egoístamente y pensé solo en mí, es más, creo que no pensé en sus hijos y su familia, ¿sino que sería ahora de mí?

Deje de asistir a controles, no conocía a nadie más en esa área, no quería volver a un proceso nuevo y tener que volver a pasar por otros controles y conceptos. Es de esa manera, que pasaron cerca de cuatro años de resistencia mía y, por otro lado, de la excesiva presión de mi familia, que finalmente, hace un mes, es decir, en julio del 2021 accedí a volver hacer todo el proceso desde el médico general, medico ortopedista y finalmente el oncólogo, para que me volviera a revisar.

Nuevamente mi hueso, sería la historia de mis huesos, porque realmente eran dos de la mano, más la lesión del humero que apareció posteriormente. Estos huesos son los que de alguna forma permitieron tejer y entretejer un evento, que fue, la ruptura ósea, ocasionada a raíz de un acto de malestar e inconformidad crónica situada en un escenario familiar y personal. Es a partir de esta, en la cual, en el presente relato, fueron emergieron 


\section{8}

varios asuntos. Asuntos que afloraron en la medida que mi escritura y mis recuerdos se iban encrucijando, pero también en la medida que empecé a tener consciencia de ellos, como, por ejemplo, la figura de mi padre, el machismo y la violencia presente en él en mis primeros años de vida, pero más aún la aceptación de mi madre a todo este asunto. Hoy en día, después de que llevan casi 50 años juntos, he vuelto a ver actitudes, discursos y prácticas en ambos, de dominación de mi padre y de humillación de mi madre, lo que me ha dolido más aún, dado que, este escrito solo tenía la intención de mostrar en palabras algo sobre mi cuerpo, pero esa parte de mi cuerpo termino a fin de cuentas vectorizando, a otros problemas que estaban ahí a la espera de ser soltados, como si estuvieran encadenados, esperando ser liberados.

Reconocer hoy, como este texto de manera medular, trata el machismo, el cual, atraviesa el presente relato, como si un puñal, atravesará un pedazo de carne y chocará contra el hueso. En toda esta narración, aparecen por ahora, cuatro niveles de machismo, que se alimentan uno de otro, en mi forma de ver: Por un lado, el mío propio, si bien no es explícito en el texto, a estado ahí presenté, sirviéndose de manera sutil, a través de estos años. Hoy, sin temor y sin sentir vergüenza alguna, reconozco públicamente que he sido machista, de hecho, aún me falta más por transformar para no causarle daño a nadie más. Otro, es el familiar, la figura paterna de mi padre y, lo que atestigüe en esos años de infancia y adolescencia, más que una prueba, fueron un recordatorio, como una especie de tatuaje, que se incrusto no solo en mi cuerpo, sino en mi mente, me alimento desafortunadamente, pero a la vez lo aborrecía, porque este tema le causo mucho dolor a mi madre. Esta dualidad, me acompaño por largo periodo. Haber reconocido que esto sucedía dentro de mi hogar fue una parte, lo más incómodo a la luz de hoy, es rememorar que esto que sucedía con mamá y papá, lo vivíamos o mejor aún yo lo vi, en el resto de mi familia, tanto paterna como materna. Recordé también, la forma como mi abuelo trataba a mi papá, a las patadas con groserías. Es decir, todo esto estaba normalizado, continúa normalizado y aceptado.

El otro nivel de machismo que señalo es el que es alimentado por la mujer. Con esto hago referencia, a que algunas mujeres, desafortunadamente por la existencia de una sociedad patriarcal que se ha mantenido en el tiempo y arraigada en sociedades y familias actuales, como por ejemplo, la mía, siguen perpetuando, aceptando y normalizando discursos, prácticas, actitudes sexistas, llevadas por hombres hacia las mujeres con el propósito de someter o demostrar la existencia de una estructura y ordenamiento social, 
esta forma de vehicular el machismo es al que hago referencia en este nivel. De hecho, en mi caso, mi madre, abuelas, tías, primas en esos tiempos e incluso aún ahora, aceptan, incluso ven como anormal, la no presencia del machismo. Todo esto me cuestiona y me incomoda. Ponerle asentó, a la otra figura de la mujer en el tema del machismo como una reguladora de él. Son ellas, desde el núcleo primario, el hogar, las que incentivan el machismo con su lenguaje: mijo no lave la ropa, yo la lavo o su hermana; dejé los platos en la mesa, yo los recojo; los hombres no lloran, sea fuerte como su papá; los hombres no juegan con muñecas; el plato de comida más grande para su papá; no importa si no queda, yo miró que como; no, usted no plancha esa ropa para eso estamos las mujeres. Cosas como esas y muchas más escuchaba a diario en casa. Entonces, si uno intentaba hacer una actividad en el hogar, que según ellas era solo de mujeres, de una vez se encargaban de corregirlo, diciendo esas no son cosas de hombres. Es como si algunas de ellas estuvieran encargadas de ajustar las desviaciones, eso, por un lado. Lo otro, era ese rol reforzador con su lenguaje y su actitud sumisa, si bien las mujeres de hoy en día han cambiado esta perversa forma de actuar, aún hay familias y mujeres que continúan con este tipo de prácticas, lo que hace que el hombre quede en una zona de confort. Aprendiendo, que esto, lo deben replicar posteriormente. Pues, todo se lo hacen y ellas están a su voluntad. Esta otra manera de machismo desde las mujeres legitima desde el propio género femenino este tipo de interacción social. A ver sido testigo de todo esto, me incomoda de manera visceral, saber que solo hasta ahora en estos tiempos, he podido comprender mejor este asunto. Me sorprendo, hoy al verme en este escrito. Pues, darme cuenta del comportamiento silencioso y cómplice que lleve por varios años, me incomoda aún más. Me cuestiono, y siento un dolor profundo, al ver hoy a mi madre de 85 años, haciendo lo mismo que vi en ella, en la relación con mi padre y todos los hombres de la familia. ¿por qué no reconocí el machismo desde el colegio y la universidad? ¿Por qué si estudie una carrera de predominio femenino, no se nos inculco o enseño teorías feministas? ¿Por qué no conocía del daño que ha hecho el patriarcado a la mujer, si ellas estuvieron tan cerca de mí?

Recordé, Poulain de la Barre, citado por Simone De Beauvoir (2010), al mencionar que fue un hombre del siglo XVII que, con su activismo y denuncias, acerca 


\section{0}

de las injusticias que se daban por la exclusión de las mujeres a la educación y otras actividades que ejercían los hombres (Beauvoir, 2010). Me llamó profundamente la atención este hecho histórico de más de 300 años, no solo porque haya sido un hombre el que lo protagonizó, sino por el contexto socio-cultural de la época en el que se desarrolló. Pero más aún, me contrastaba con Barre, llegando a sentir un desagrado conmigo mismo. Dado que, me parece un acto de gallardía y a la vez revolucionaria, la actitud de Barre; en contra posición a mi postura pasiva, que penosamente asumí, durante tantos años. Me sigo cuestionando ¿cómo fue posible que no reaccionará con vehemencia y desacomodo, a tanta injusticia, en la piel de mi madre? Si yo fui testigo de varias Injusticias, provocadas por hombres, en especial mi padre. Si Barre, siendo adolescente, ya se planteaba y problematizaba este asunto de las brechas de género, ¿cómo fue posible que no me diera cuenta de esto? ¿Me dio miedo enfrentar a mi padre? En esta introspección que tengo, creo que mi actitud fue la más básica y simplista por llamarlo de algún modo, cómoda. Pues, lo que hice al terminar la universidad, fue alejarme de mis padres. Tenía mis motivos, sobre todo con él, pero al mismo tiempo, la había abandonado a ella para que siguiera subordinada a la estructura patriarcal de mi padre, eso me acompaño en mis pensamientos.

Afincándome en la última forma de machismo a la que me referiré, la cual, está dada por el machismo en mi área de praxis. Con lo anterior, hago referencia a todas esas prácticas, discursos reproducidos y ejecutados por algunas de mis profesoras y de manera paralela, por algunas de mis compañeras hacia nosotros los hombres; en otras palabras, es aquel machismo, ejercido de la mujer al hombre y que, se veía expresado en su máxima plenitud en los actos de castigo, dolor y opresión que estaban a la vez subsumidos en los actos pedagógicos, actos que regularmente ejercían hacia algunos estudiantes hombres. En donde, yo estaba incluido ahí. Es decir, desde la pedagogía del castigo y el disciplinamiento de los cuerpos, tal como lo señala Segato y Foucault, (Foucault, 2008; Segato, 2018). De tal modo, esos cuerpos que eran disciplinados, dentro de un orden de discurso, no son, sino el resultado de las huellas de la tradición que promueve prácticas sociales. Prácticas que están en los tuétanos de la estructura patriarcal, lo cual, hace que en el patriarcado la diferencia sexual se presenté como razón suprema, base y fundamento de la discriminación que inspira su ideología (Beauvoir, 2010). 
Ahora bien, estas prácticas sociales entorno a mi disciplina, la enfermería y que fueron llevadas a cabo por mis profesoras, me hicieron recordar aspectos del origen, de lo que se conoce como la enfermería moderna. Florece Nightingale, instituyó una clara correspondencia entre la feminización de la práctica de la enfermería. Era un deber exclusivo de las mujeres, lo que llevó a que, en las instituciones epistémicas de formación en enfermería de esa época fueran únicamente admitidas mujeres para formarse como enfermeras (Ehrenreich \& English, 1973). En palabras de Narváez et al. citando a Florence Nightingale (Narváez et al., 2010):

Para ser una buena enfermera es necesario ser una buena mujer de lo contrario no se es otra cosa que una campanilla [...] Jamás he puesto en duda que el más grande de los deberes de una mujer consiste en prodigar sus cuidados a niños, ancianos, enfermos $y$ pobres, además de tener siempre un carácter obediente hacia el médico.

Prácticas estas que sin lugar a dudas están enraizadas desde sus orígenes dentro de un sistema patriarcal y que a la luz de hoy algunos las mitologizan y naturalizan, a pesar de las transformaciones disciplinares en los últimos sesenta años.

Utilizando la metáfora de Winnie Tomm del yo permeable, en donde, la persona esta interconectada con los demás, sin experimentar la pérdida de uno mismo (Tomm, 1995). Igualmente, como señala Marilyn Metta, con la idea del cuerpo permeable. De manera que, el cuerpo permeable se convierte en un lugar de conexión, de diferencias entre el cuerpo de uno mismo y el cuerpo de los demás (Metta, 2013). En otras palabras, existe una movilidad constante entre cuerpos, y esta presencia se ve en el texto. Por eso, también podría decirse, que estos espacios en blanco o en vacío, que se crean en este tipo de narración en capas, como lo ha sido el presente escrito, deben ser llenados por el lector, con su imaginación, tal como lo señala Wolfgang Iser y citado por Tornero (Tornero, 2005). De igual forma, se comporta también como unas membranas permeables como señala Metta, en las que hay presencia de una intercambiabilidad y reciprocidad de un conocimiento que se encuentra encarnado y que se está narrando y, por otro lado, en el conocimiento del que lo lee y crítica el texto (Metta, 2013). En esta interacción dialógica las membranas indican un comportamiento vivo, activo, fluido, cambiante, propio de un cuerpo. Así, como los espacios en blanco crean esa posibilidad de interconectar con el 
texto de manera sistemática y activa; la metáfora de las membranas permeables, le da sostén para mantener viva, la presencia de la historia narrada.

Todo lo que ha sido escrito por los hombres sobre las mujeres es sospechoso, ya que ellos son a la vez juez y parte

Poulain de la Barre

\section{BIBLIOGRAFÍA}

o Beauvoir, S. (2010). The second sex. Paris: Éditions Gallimard.

o Bochner, A. P. (1997). It's About Time: Narrative and the Divided Self. Qualitative Inquiry, 3(4), 418-438. https://doi.org/10.1177/107780049700300404

o Bourdieu, P. (1993). Sociology in Question (First English). SAGE Publications Ltd.

o Castro, R. (2014). Génesis y práctica del habitus médico autoritario en México. Revista Mexicana de Sociología, 76(2), 167-197.

o Ehrenreich, B., \& English, D. (1973). Brujas, parteras y enfermeras. Una historia de sanadoras. The Feminist Press.

o Ellis, C. (2016). Revision: Autoethnographic Reflections on Life and Work. Routledge.

o Foucault, M. (2008). Tecnologías del yo y otros textos afines. Paidós.

o Metta, M. (2013). Putting the Body on the Line: Embodied Writing and Recovery through Domestic Violence. En Handbook of Autoethnography (pp. 486-509). Left Coast Press.

o Narvaéz, A., Martinez, J., \& Pérez, B. (2010). Revisitando a Florence Nightingale desde una perspectiva de género. Index Enferm, 19(4).

o Segato, R. (2013). La Escritura En El Cuerpo. Tinta Limon.

o Segato, R. (2018). Contra-pedagogías de la crueldad (Primera). Prometeo Libros.

o Siles, J. (2000). Antropología narrativa de los cuidados. Consejo de Enfermería de la Comunidad Valenciana, Alicante.

o Siles, J., Cibanal, J., Galao, R., Molero, D., Solano, C., Gallardo, Y., \& García, E. (2005). Antropología narrativa y situaciones vida salud en la obra de Mario Benedetti y Octavio Paz. Cultura de los Cuidados, 9(17), 59-67. http://dx.doi.org/10.14198/cuid.2005.17.10

o Tomm, W. (1995). Bodied Mindfulness: Women's Spirits, Bodies and Places (First Edition). Wilfrid Laurier University Press.

o Tornero, A. (2005). Indeterminaciones y espacios vacíos en Roman Ingarden y Wolfgang Iser. Anuario de letras modernas. 
o Torres, P., \& Delgado, D. (2018). La Naturalización del Machismo através de la Familia. Universidad San Francisco de Quitó USFQ Colegio de Comunicación y artes contemporáneas.

o Urias, M. (2016). El machismo: ¿han cambiado las cosas? Culture, Society and Praxis, 9(2), 1-8. 